Res., Soc. Dev. 2019; 8(6):e39861069

ISSN 2525-3409 | DOI: http://dx.doi.org/10.33448/rsd-v8i6.1069

\title{
A Integração e a Inclusão Escolar no panorama histórico patrimonial-burocrático
}

$$
\text { brasileiro }
$$

\section{Integration and School Inclusion in the brazilian bureaucratic-heritage historic panorama}

La Integración y la Inclusión Escolar en el panorama histórico patrimonial-burocrático brasileño

Recebido: 25/03/2019 | Revisado: 25/03/2019 | Aceito: 29/03/2019 | Publicado: 30/03/2019

\section{Olgda Laria Borges de Paula}

ORCID: https://orcid.org/0000-0002-7529-8759 Instituto Federal de Educação, Ciência e Tecnologia de Mato Grosso - IFMT, Brasil E-mail: olgda.paula@cba.ifmt.edu.br Edione Teixeira de Carvalho ORCID: https://orcid.org/0000-0002-1208-3961 Instituto Federal de Educação, Ciência e Tecnologia de Mato Grosso - IFMT, Brasil E-mail: edione.carvalho@svc.ifmt.edu.br

\section{Resumo}

O presente estudo analisa a inserção dos alunos com necessidades educacionais específicas nas instituições de ensino regular, tendo em vista as características da sociedade brasileira marcadamente patrimonial-burocrática. As metodologias utilizadas foram a pesquisa documental, relativa à legislação vigente que preconiza o atendimento aos discentes com deficiência, transtornos globais do desenvolvimento e altas habilidades - Lei $\mathrm{n}^{\circ}$ 9.394, de 20 de dezembro de 1996; Resolução CNE/CEB n 2, de 11 de setembro de 2001; Política Nacional de Educação Especial na Perspectiva da Educação Inclusiva de 2008; Lei $n^{\circ}$ 13.146, de 6 de julho de 2015 - e a pesquisa bibliográfica de produções científicas atinentes ao assunto abordado. Como resultado, considera-se que as normativas legais possibilitam a inclusão desses estudantes no sistema de ensino regular. Entretanto, esse modelo híbrido de patrimonialismo e burocracia, obstaculiza mudanças substanciais, pois à tentativa de implantação da inclusão nas instituições educacionais, opõem-se as práticas tradicionais dos docentes, mantendo os pressupostos da integração escolar. Conclui-se que a formação continuada dos professores, recomendada pelas normativas legais pesquisadas, cria a 
possibilidade de enfraquecer aspectos do fazer pedagógico arraigados em valores patrimoniais, garantindo a eficácia da inclusão escolar.

Palavras-chave: Integração Escolar; Inclusão Escolar; Patrimonialismo; Burocracia.

\section{Abstract}

The present study analyzes the insertion of students with specific educational needs in institutions of regular education, considering the characteristics of Brazilian society markedly patrimonial-bureaucratic. The methodologies used were documentary research, in relation to the current legislation that advocates attention to students with disabilities, global developmental disorders and high skills - Law 9,394 of December 20th, 1996; CNE / CEB Resolution No. 2 of September 11th, 2001; National Policy on Special Education in the Perspective of Inclusive Education 2008; Law No. 13,146, of July 6th, 2015 - and the bibliographic research of scientific productions concerning the matter addressed. As a result, it is considered that the legal regulations allow the inclusion of these students in the regular education system. However, this hybrid model of patrimonialism and bureaucracy, hinders substantial changes, because the attempt to implement inclusion in educational institutions, oppose traditional practices of teachers, maintaining the presuppositions of school integration. It is concluded that the continuous training of teachers, recommended by the legal regulations researched, creates the possibility of weakening pedagogical aspects rooted in heritage values, guaranteeing the effectiveness of school inclusion.

Keywords: School Integration; School Inclusion; Patrimonialism; Bureaucracy.

\section{Resumen}

El presente estudio analiza la inserción de los alumnos con necesidades educativas específicas en las instituciones de enseñanza regular, teniendo en vista las características de la sociedad brasileña marcadamente patrimonial-burocratica. Las metodologías utilizadas fueron la investigación documental, relativa a la legislación vigente que preconiza la atención a los alumnos con discapacidad, trastornos globales del desarrollo y altas habilidades - Ley $\mathrm{n}^{\circ}$ 9.394, de 20 de diciembre de 1996; Resolución CNE / CEB nº 2, de 11 de septiembre de 2001; Política Nacional de Educación Especial en la Perspectiva de la Educación Inclusiva de 2008; Ley $\mathrm{n}^{\circ}$ 13.146, de 6 de julio de 2015 - y la investigación bibliográfica de producciones científicas concernientes al asunto abordado. Como resultado, se considera que las normativas legales posibilitan la inclusión de estos estudiantes en el sistema de enseñanza regular. Sin embargo, ese modelo híbrido de patrimonialismo y burocracia, obstaculiza cambios 
sustanciales, pues al intento de implantación de la inclusión en las instituciones educativas, se opone a las prácticas tradicionales de los docentes, manteniendo los presupuestos de la integración escolar. Se concluye que la formación continuada de los profesores, recomendada por las normativas legales investigadas, crea la posibilidad de debilitar aspectos del hacer pedagógico arraigados en valores patrimoniales, garantizando la eficacia de la inclusión escolar.

Palabras clave: Integración Escolar; Inclusión Escolar; patrimonialismo; Burocracia.

\section{Introdução}

A Lei de Diretrizes e Bases da Educação Nacional, no 9.394/96, a Resolução CNE/CEB n $n^{\circ}$, de 11 de setembro de 2001, a Política Nacional de Educação Especial na Perspectiva da Educação Inclusiva de 2008, e a Lei n 13.146, de 6 de julho de 2015, apontam para o planejamento e organização de propostas inclusivas para os discentes com necessidades educacionais específicas nas escolas regulares.

A política educacional brasileira preconiza a educação inclusiva por meio da legislação vigente. Entretanto, os paradigmas da integração e da inclusão escolar convivem na maior parte dos sistemas escolares (Glat \& Blanco, 2007; Sassaki, 2006). Assim, apesar de as instituições educacionais apresentarem o discurso da inclusão utilizam de fato os pressupostos da integração. A inclusão educacional representa a inserção incondicional do discente, enquanto a integração significa a inserção somente dos alunos que conseguem se adequar à estrutura pedagógica e organizacional da escola. Para Prieto (2006), embora os princípios da inclusão escolar venham se fortalecendo, ainda há a preponderância do modelo integracionista nas práticas escolares.

Portanto, não bastam dispositivos legais em uma sociedade semitradicional para garantir a efetiva concretização, no cotidiano das escolas, de práticas que levem a conceber estas unidades educacionais como espaço público, pois ao processo de implantação de normas racionais-legais contrapõem-se as práticas tradicionais. Tais dispositivos, frequentemente, esbarram nos próprios limites impostos pela constituição das sociedades.

As características recebidas durante o processo colonizador se consolidaram em nossa cultura, desenvolvendo em solo brasileiro padrões institucionais característicos do patrimonialismo (Holanda, 1978). Sendo assim, os princípios universalistas e igualitários, ao longo do nosso processo histórico, foram ajustados a formas de particularismos, engendrando um modelo híbrido em que o patrimonialismo e a burocracia racional coexistem, o que 
dificulta as mudanças. Evidentemente, a coexistência entre universalismo e particularismo não representa uma particularidade brasileira, mas suas configurações características, como constitutivas do tecido social, restringem os contextos dentro dos quais se dá a ação coletiva.

Compreender os obstáculos que impedem a efetiva concretização da inclusão escolar no cotidiano das instituições educacionais brasileiras, no que concerne ao caráter patrimonial da cultura e da formação estatal brasileira, é de extrema relevância na medida em que só é possível superar as dificuldades advindas de um processo como este, ao passo em que se conhecem os impeditivos. Conhecendo os limites que criam obstáculos ao processo inclusão é possível criar estratégias de ação para a sua superação, permitindo que logre êxito.

Portanto, este estudo objetivou analisar o processo de implantação da inclusão de alunos com necessidades educacionais específicas nas instituições educacionais regulares, tendo em vista a formação de nossa sociedade marcadamente patrimonialista.

\section{Aporte Histórico e Normativo da Integração e Inclusão Escolar}

O paradigma integracionista foi incorporado à história da Educação Especial no final da década de 60 e início dos anos 70, quando, conforme Marques (1999), o chamado princípio de normalização foi elaborado por um grupo de estudiosos da Escandinávia. Ele foi difundido por todo o mundo, tornando-se o pilar teórico-prático dos estudos sobre o atendimento aos indivíduos com necessidades específicas. Os movimentos conduzidos por deficientes foram responsáveis por desenvolver a consciência crítica da sociedade a respeito dos seus direitos, mostrando as formas injustas com que eram tratados e a indispensabilidade de mudanças sociais profundas.

A filosofia da normalização, conforme Mendes (1994), partia do princípio de que todos com deficiência teriam o direito de vivenciar modos de vida o mais próximo possível do restante da população. Isso significava que as condições adequadas seriam as que mais se assemelhassem aos ambientes experenciados pelas outras pessoas. Assim, os indivíduos com deficiência seriam melhor atendidos na medida em que lhes fossem ofertados o mesmo atendimento ou com o mínimo de limitação em relação ao disponibilizado aos demais.

Nos países europeus, observaram-se alguns aparatos legais e ações dos próprios cidadãos para estabelecer pressupostos e práticas de cunho integracionista. Essas atuações pela integração das pessoas com deficiência podem ser atribuídas a três fatores. O primeiro deles refere-se às duas guerras mundiais. 
No que diz respeito às Grandes Guerras, duas foram as principais [...] implicações ao movimento integracionista. A primeira foi o retorno [...] de indivíduos fisicamente debilitados ou deficientes, causando a necessidade de se criar, implantar e reformular programas de reintegração destes indivíduos na sociedade. A segunda constitui-se na escassez de mão-de-obra ocasionada pelo curto espaço de tempo entre as duas Guerras e, obviamente, pela perda de soldados. Estes dois fatores em conjunção promoveram o aparecimento de programas de educação, saúde e treinamento específico para funções trabalhistas de deficientes que visavam, ao mesmo tempo que reintegrar tais indivíduos na sociedade, preencher lacunas da força de trabalho [...] originadas pelas duas Guerras (Santos, 1995, p. 22).

A segunda condição para o surgimento da integração foi o fortalecimento dos movimentos pelos Direitos Humanos. Logo, o direcionamento da integração dos indivíduos com deficiência dar-se-á com base em seus direitos, ao contrário do pós-guerra em que a perspectiva era paternalista ou para ocupar postos de trabalho.

O último motivo que influenciou a oficialização do movimento integracionista europeu foi o avanço científico no campo educacional, médico e psicológico, enfatizando que as deficiências não implicariam, necessariamente, na impossibilidade de aprendizagem. Nesse período, surgem abordagens pedagógicas centradas no aluno, na formação do indivíduo como futuro cidadão (Santos, 1995).

No modelo integrativo, as pessoas com deficiência são inseridas socialmente, desde que sejam capazes de se adequar aos requisitos dos serviços separados, contornar os obstáculos que existem nos espaços físicos, seguir os procedimentos tradicionais sem nenhuma alteração e desempenhar individualmente os papéis sociais (Sassaki, 2006). Assim, a integração escolar é uma maneira de inserção que depende do educando, isto é, "do nível de sua capacidade de adaptação às opções do sistema escolar” (Mantoan, 1998, p. 32).

A tônica da integração acabou por se constituir na transmissão da responsabilidade pela inserção à pessoa com deficiência. Ela é que deveria estar se modificando para integrarse ao ambiente institucional. A integração procurou reduzir as diferenças entre os indivíduos com necessidades específicas e o restante da população, pois estas constituiriam em um impeditivo à sua aceitação social.

[...] a integração social, afinal de contas, tem consistido no esforço de inserir na sociedade pessoas com deficiência que alcançaram um nível de competência compatível com os padrões sociais vigentes. A integração tinha e tem o mérito de inserir a pessoa com deficiência na sociedade, sim, mas desde que ele esteja de alguma forma capacitado a superar as barreiras físicas, programáticas e atitudinais nela existentes. Sob a ótica dos dias de hoje, a integração constitui um esforço unilateral tão somente da pessoa com deficiência e seus aliados (a família, a instituição especializada e algumas pessoas da comunidade que abracem a causa da inserção social), sendo que estes tentam torná-la mais aceitável no seio da sociedade (Sassaki, 2006, p. 33). 
ISSN 2525-3409 | DOI: http://dx.doi.org/10.33448/rsd-v8i6.1069

No âmbito escolar, o paradigma da integração ficou condicionado ao tipo de limitação que o discente apresentava, permanecendo mais distante desse espaço quem menos se ajusta às suas normas disciplinares e aos seus arranjos administrativos e pedagógicos.

Na década de 90, há a ascensão do paradigma da inclusão educacional que tem como princípio basilar o entendimento de que todos os discentes devem ser atendidos nas instituições educacionais regulares independentemente de suas condições existenciais. A inclusão escolar traz a concepção de que é preciso viabilizar o acesso e a permanência com êxito de todos os alunos e os procedimentos de seleção e discriminação são dissipados pela utilização de mecanismos de identificação e eliminação de obstáculos à aprendizagem (Glat \& Blanco, 2007).

A Lei $n^{\circ}$ 9.394, de 20 de dezembro de 1996, que estabelece as diretrizes e bases da educação nacional, determina no art. $4^{\circ}$ que é dever do Estado assegurar:

\begin{abstract}
III - atendimento educacional especializado gratuito aos educandos com deficiência, transtornos globais do desenvolvimento e altas habilidades ou superdotação, transversal a todos os níveis, etapas e modalidades, preferencialmente na rede regular de ensino (Brasil, 1996, grifo nosso).
\end{abstract}

A Resolução CNE/CEB n 2, de 11 de setembro de 2001, que institui as Diretrizes Nacionais para a Educação Especial na Educação Básica, estipula que:

Art. $7^{\circ} \mathrm{O}$ atendimento aos alunos com necessidades educacionais especiais deve ser realizado em classes comuns do ensino regular, em qualquer etapa ou modalidade da Educação Básica (Brasil, 2001).

Essa normativa legal destaca o caráter extraordinário e transitório em que devem ser mantidos os serviços especializados, levando-se em consideração os pressupostos da educação inclusiva. Além disso, dispõe que precisa ser ofertada a formação continuada aos docentes no exercício da profissão. Ao considerar a inclusão escolar, estabelece o currículo flexibilizado e adaptado e práticas pedagógicas diferenciadas para atendimento aos discentes com necessidades educacionais específicas.

A Política Nacional de Educação Especial na Perspectiva da Educação Inclusiva de 2008 dispõe que o seu objetivo é garantir a inclusão dos alunos com necessidades escolares específicas no ensino regular, possibilitando a aprendizagem por meio de soluções às demandas individuais e assegurando a formação de profissionais da área educacional para que a inclusão escolar ocorra (p. 14).

A Lei $n^{\circ}$ 13.146, de 6 de julho de 2015, que institui a Lei Brasileira de Inclusão de Pessoa com Deficiência (Estatuto da Pessoa com Deficiência), regulamenta que cabe ao poder público propiciar um "sistema educacional inclusivo" e, conforme inciso II do artigo 28, o 
"aprimoramento dos sistemas educacionais, visando a garantir condições de acesso, permanência, participação e aprendizagem, por meio da oferta de serviços e de recursos de acessibilidade que eliminem as barreiras e promovam a inclusão plena” (Brasil, 2015).

A instituição escolar para ser inclusiva precisa assegurar a formação permanente de seus profissionais para atender a todos os alunos e modificar seus pressupostos curriculares, promovendo um processo de ensino e aprendizagem adequado ao desenvolvimento dos discentes e fomentando a inclusão educacional (Glat \& Blanco, 2007).

A inclusão consiste em um processo mútuo, em que as pessoas com necessidades educacionais específicas e a sociedade esforçam-se para sanar os problemas, deliberar acerca de soluções e proporcionar a igualdade de oportunidades. Esse paradigma baseia-se nos princípios de reconhecimento das diferenças, da valorização de cada um, da convivência com a diversidade e da aprendizagem por meio da cooperação.

\begin{abstract}
A inclusão social, portanto, é um processo que contribui para a construção de um novo tipo de sociedade através de transformações, pequenas e grandes, nos ambientes físicos (espaços internos e externos, equipamentos, aparelhos e utensílios, mobiliário e meio de transporte) e na mentalidade de todas as pessoas, portanto também da própria pessoa com necessidades especiais (Sassaki, 2006, p. 40).
\end{abstract}

A diferença entre esses dois paradigmas reside no fato de que na Integração Escolar, os alunos só são inseridos nas escolas regulares ao passo em que superam as suas dificuldades, ou seja, ao comprovarem a capacidade de adequar-se à instituição educacional. $\mathrm{Na}$ Inclusão Escolar, é a instituição que precisa romper com barreiras físicas e atitudinais, promovendo a flexibilização do currículo para que os discentes possam ser inseridos.

Entretanto, nas unidades educacionais persevera uma tensão constante entre o processo de implantação de normas racionais-legais, compatíveis com a burocracia, e as práticas dos docentes que operam numa perspectiva tradicional, resultante do semitradicionalismo brasileiro.

\title{
3. Patrimonialismo e Burocracia: aspectos característicos e panorama brasileiro
}

Max Weber (1972; 1986) descreveu a burocracia como um "tipo ideal", isto é, uma abstração construída a partir de elementos empíricos, por meio da qual as características extremas desse fenômeno são descritas, sem que organização alguma, em seu modelo puro de burocracia, possa ser encontrada na realidade. Assim, nem toda associação formal possuirá o conjunto das características presentes no tipo ideal de burocracia. Este pode ser utilizado 
como um modelo que possibilita determinar em que aspecto particular uma organização é burocrática. Dentre os tipos de dominação, destaca-se, nesse estudo, as:

1. de caráter racional: baseada na crença na legitimidade das ordens estatuídas e do direito de mando daqueles que, em virtude dessas ordens, estão nomeados para exercer a dominação (dominação legal) ou

2. de caráter tradicional: baseada na crença cotidiana na santidade das tradições vigentes desde sempre e na legitimidade daqueles que, em virtude dessas tradições, representam a autoridade (dominação tradicional) [...] (Weber, 1972, p. 141).

A dominação patrimonial, de caráter tradicional, é a originariamente guiada pelo hábito e se exerce em consequência de pleno direito pessoal. Os funcionários administrativos não têm competência fixa segundo disposições objetivas, estrutura hierárquica racional e fixa de cargos, designação normatizada por contrato livre, promoção ordenada, formação profissional como norma e, frequentemente, salário fixo e pago em dinheiro.

$\mathrm{Na}$ dominação racional-legal, a legitimidade origina-se da crença na justiça da lei e baseia-se em normas legais racionalmente definidas. Os governantes obedecem às leis, pelo fato de creem que elas são decretadas segundo procedimentos corretos. Neste tipo de dominação, acredita-se que o governante exerce o poder, porque atingiu tal posição por meio de nomeações consideradas legais. Assim, a dominação legal assenta-se na primazia da regra racional-legal, cuja forma pura manifesta-se na burocracia.

\footnotetext{
Dominação legal em virtude de estatuto. Seu tipo mais puro é a dominação burocrática. [...] qualquer direito pode ser criado e modificado mediante um estatuto sancionado corretamente quanto à forma. A associação dominante é eleita ou nomeada, e ela própria e todas as suas partes são empresas. [...]. O quadro administrativo consiste de funcionários nomeados [...] e os subordinados são membros da associação [...] (Weber, 1986, pp. 128-9).
}

$\mathrm{Na}$ dominação racional, as categorias fundamentais são um exercício contínuo e vinculado a regras, dentro de competência determinada, o que implica um âmbito objetivamente definido, devido à distribuição dos serviços obrigatórios, com atribuição de poderes de mando eventualmente requeridos e limitação dos meios coercitivos admissíveis e das possibilidades de sua aplicação.

A burocracia, conforme Weber (1974), possibilita um nivelamento entre os atores sociais em suas relações, pois a regularidade abstrata rejeita o privilégio. A organização burocrática favorece essa igualdade e a exigência de garantias legais contra a arbitrariedade na medida em que requer critérios objetivos, formais e racionais de administração em contraposição ao domínio patrimonial.

O formalismo e a impessoalidade da burocracia rompem com o informalismo e o caráter pessoal presente na dominação patrimonial uma vez que se caracteriza pela 


\title{
Res., Soc. Dev. 2019; 8(6):e39861069
}

ISSN 2525-3409 | DOI: http://dx.doi.org/10.33448/rsd-v8i6.1069

predominância de estrutura hierárquica dos cargos, pela existência de normas e regras escritas que regulam os comportamentos individuais e pela divisão metódica vertical e horizontal das tarefas.

\begin{abstract}
A dominação legal do tipo burocrática, a obediência se dá não à pessoa, mas à regra que estabelece quem e em que medida deve obedecer. Quem ordena é o superior que possui direito de mando dentro de suas competências legitimadas pela regra estatuída. A delimitação e a especialização da competência se baseiam na utilidade objetiva e nas exigências estipuladas para a atividade profissional do funcionário. As condições de serviço são estabelecidas num contrato de trabalho, o pagamento é fixo, é graduado de acordo com o cargo ocupado, sendo assegurado direito de ascensão conforme as regras estabelecidas, não devendo ser influenciada pelas questões e interesses pessoais, sentimentos e caprichos. A hierarquia estabelece os parâmetros para a obediência, colocando os inferiores como subordinados aos superiores. A base do funcionamento técnico é a disciplina no serviço (Weber,1978, pp. 128-9).
\end{abstract}

Um aspecto essencial da racionalidade burocrática relaciona-se com o fato de as organizações serem conduzidas por administradores profissionais, preparados para o cargo, que fazem uso de conhecimento técnico especializado, alcançado geralmente por meio de uma exposição prolongada à ação de agentes voltados a tarefas de educação e treinamento. $\mathrm{O}$ funcionamento eficiente das burocracias deve-se ao uso do conhecimento especializado. Assim, torna-se indispensável funcionários especialmente treinados para executarem as diferentes funções. Os administradores burocráticos são submetidos a testes e exames e, ao serem escolhidos, apresentam títulos.

O administrador profissional é antes de tudo um especialista. Esta é uma característica fundamental. [...] o uso do conhecimento especializado é essencial para o funcionamento eficiente. São necessários, pois, especialistas, [...] especialmente treinados para exercer as diversas funções criadas através do processo de divisão do trabalho, que geralmente devem ter um diploma e/ou experiência para poder ocupar o cargo. Seus conhecimentos, porém, não devem limitar-se à sua especialidade (Motta \& Pereira, 1980, p. 34).

O Estado brasileiro seguiu um curso particular de organização que combinou características da burocracia com ordenamentos patrimonialistas. O patrimonialismo, estrutura político-social, perdurou, da Colônia à República, em relação a todas as mudanças fundamentais. Essa característica adaptou-se e modelou a realidade brasileira, sobrevivendo e incorporando os ordenamentos burocráticos, de caráter racional. A máquina estatal brasileira reproduziu os mesmos vícios do Estado português.

Em lugar de renovação, o abraço lusitano produziu uma social enormity, segunda a qual velhos quadros e instituições anacrônicas frustram o florescimento do mundo virgem. Deitou-se remendo de pano novo em vestido velho, vinho novo em odres velhos, sem que o vestido se rompesse nem o odre rebentasse (Faoro, 1989, p. 748). 
A coexistência de formas burocráticas e patrimoniais, da pessoalidade e impessoalidade, da pessoa e indivíduo é resultado da maneira como foi constituindo-se a sociedade brasileira, ou seja, sempre buscou-se transmutar para o Brasil, ainda arraigado aos seus tradicionalismos, como a economia escravocrata, as concepções de uma grande democracia.

Nessa perspectiva, em "todas as culturas, o processo pelo qual a lei geral suplanta a lei particular faz-se acompanhar de crises mais ou menos graves e prolongadas, que podem afetar profundamente a estrutura da sociedade" (Holanda, 1978, p. 102). A crise que seguiu a passagem para o trabalho industrial mostra as dificuldades que obstaculizam a supressão da ordem familiar por outra, onde as instituições e as relações sociais, assentadas em princípios abstratos, substituem os laços de afeto e de sangue. Assim, em sociedades onde predomina e assenta a ideia de família, principalmente onde prevalece a família do tipo patriarcal, como no Brasil, a formação e progressão da sociedade segundo concepções modernas tende a ser precária e a lutar contra fortes restrições.

“Ao contrário, é possível acompanhar, ao longo de nossa história, o predomínio constante das vontades particulares que encontram seu ambiente próprio em círculos fechados e pouco acessíveis a uma ordenação impessoal” (Holanda, 1978, p. 106). Nesses círculos, o familiar indubitavelmente foi o que se exprimiu com mais força na sociedade brasileira. Isso acontece até nos meios em que as instituições democráticas, edificadas em pressupostos imparciais e gerais, objetivam fundar a coletividade em princípios antiparticularistas.

No Brasil, existem duas bases sobre as quais os indivíduos pensam o seu sistema. Segue-se, no caso das leis gerais, o código burocrático ou a vertente impessoal, universalizante e igualitária como eixo de ação. No entanto, nas situações concretas, utiliza-se o código das relações e da moralidade pessoal, aplicando a vertente do "jeitinho" e da "malandragem". "Na primeira escolha, nossa unidade é o indivíduo; na segunda, a pessoa" (Damatta, 1997, p. 218). Portanto, têm-se duas éticas, uma impessoal e outra pessoal, baseada na relação, mantendo-se, dessa forma, uma segmentação tradicional.

Assim, nas instituições educacionais, a lógica das relações pessoais também está presente. Gandini (2005) atenta para essa situação ao observar a predominância dos vínculos patrimoniais no cotidiano pedagógico. Características da formação patrimonial se manifestam nos relacionamentos educacionais, considerados pela autora como marcadamente ‘domésticos' (p. 219).

Desse modo, observa-se o paradoxo resultante no processo social de constituição da sociedade brasileira, em que a estrutura organizacional do sistema educacional tem como base 
os princípios burocráticos, mas a prática dos entes educacionais é alicerçada em princípios patrimoniais, em virtude da predominância das relações e da pessoalidade sobre o caráter impessoal, esse último característico do processo de burocratização.

\section{Metodologia}

Esta investigação consiste em uma pesquisa documental tem como fonte os documentos (Severino, 2007). As fontes documentais podem ser, dentre outras, "leis, regulamentos, normas, pareceres, cartas, memorandos, diários pessoais, autobiografias, jornais, revistas, discursos, roteiros de programas de rádio e televisão até livros, estatísticas e arquivos escolares" (Lüdke \& André, 2017, p. 45).

As fontes selecionadas para a pesquisa são os documentos legais em vigência referentes ao atendimento de alunos com necessidades educacionais específicas, ou seja, a Lei $\mathrm{n}^{\circ}$ 9.394, de 20 de dezembro de 1996, que estabelece as diretrizes e bases da educação nacional; a Resolução CNE/CEB n ${ }^{\circ}$ 2, de 11 de setembro de 2001, que institui as Diretrizes Nacionais para a Educação Especial na Educação Básica; a Política Nacional de Educação Especial na Perspectiva da Educação Inclusiva de 2008; e a Lei $n^{\circ} 13.146$, de 6 de julho de 2015, que institui a Lei Brasileira de Inclusão de Pessoa com Deficiência (Estatuto da Pessoa com Deficiência).

Nos procedimentos metodológicos, foi utilizada também a pesquisa bibliográfica que se caracteriza pela utilização de fontes secundárias. Assim, consiste na análise da produção científica publicada para o levantamento e o exame do que se produziu acerca de um tema específico. Logo, a pesquisa bibliográfica é desenvolvida com base em material difundido composto, principalmente, de livros, artigos de periódicos/revistas e publicações avulsas.

A pesquisa bibliográfica é aquela que se realiza a partir do registro disponível, decorrente de pesquisas anteriores, em documentos impressos, como livros, artigos, teses e etc. Utiliza-se de dados ou de categorias teóricas já trabalhados por outros pesquisadores e devidamente registrados. Os textos tornam-se fontes dos temas a serem pesquisados. O pesquisador trabalha a partir das contribuições dos autores dos estudos analíticos constantes nos textos (Severino, 2007, p. 122).

Esse método de pesquisa permite ao pesquisador o contato com vários documentos científicos elaborados sobre um objeto de estudo, por meio das quais é exequível o esclarecimento dos constructos epistemológicos de uma formulação teórica, propiciando a investigação de problemas ainda não solucionados. Portanto, conforme Marconi e Lakatos (1990, p. 66), “a pesquisa bibliográfica não é mera repetição do que já foi dito ou escrito 
sobre certo assunto, mas propicia o exame de um tema sob novo enfoque ou abordagem, chegando a conclusões inovadoras".

As obras selecionadas relacionam-se ao objeto de estudo, em conformidade com as temáticas que lhe são correlatas. As fontes analisadas são as publicações de 1990 a 2015 que tratam da temática pesquisada. Ademais, outras produções de autores clássicos são usadas para possibilitar o entendimento do contexto histórico brasileiro.

\section{Resultados}

A inclusão de alunos com necessidades educacionais específicas, isto é, com deficiência, transtornos globais do desenvolvimento e altas habilidades no sistema escolar regular se constrói como parte dos mapas culturais pré-existentes. Assim, no recinto educacional, essa questão não pode ser analisada sem levar em consideração o quadro histórico que ocasionou formas singulares de relações entre particularismo e universalismo, patrimonialismo e burocracia.

Portanto, no âmbito institucional, esse modelo híbrido patrimonial-burocrático limita a inclusão de parcelas de alunos excluídos do sistema regular de ensino, pois o patrimonialismo neutraliza o impacto das mudanças promovidas pela norma racional-legal. Em virtude disso, coexistem nas escolas brasileiras a integração e a inclusão educacional, visto que às tentativas de alteração do panorama escolar brasileiro, por meio da legislação vigente, opõem-se os valores e as práticas tradicionais dos docentes. A capacidade da estrutura patrimonial brasileira de adaptar-se diante de pressões externas, absorvendo os aspectos racionalizantes da burocracia somente em sua aparência, impede transformações substanciais no cenário de implementação do paradigma inclusivo.

O antagonismo entre patrimonialismo e burocracia, abordado por Max Weber (1972; 1974; 1986), pode ser percebido pelo estabelecimento das normativas legais que, enquanto instrumento burocrático legalmente instituído, objetivam regular o comportamento dos entes educacionais. Entretanto, os valores patrimoniais presentes em nossa cultura impedem que o âmbito educacional seja regido por essas normas, pois, nas organizações patrimonialistas, o foco não é a primazia da regra racional. É dessa forma que o caráter patrimonial da formação social brasileira dificulta a concretização dos pressupostos dos dispositivos legais no cotidiano das instituições escolares.

O Brasil vivenciou progressos no transcurso da burocratização. No entanto, o sistema burocrático não conseguiu invalidar os modelos fundantes de dominação não racionais 
(Mendonça, 2000). Desse modo, a dominação tradicional manteve-se, estabelecendo um padrão híbrido burocrático-patrimonial. É nessa existência simultânea e antagônica de traços tradicionais e racionais que se encontra uma das características mais singulares da ordenação das instituições brasileiras. A burocracia e o patrimonialismo justapõem-se, postergando o advento de uma estrutura que propicie a anulação do atraso e, consequentemente, da inclusão dos discentes com necessidades educacionais específicas no sistema regular de ensino.

\section{Considerações finais}

Os obstáculos ao processo de inclusão dos alunos com necessidades educacionais específicas nas instituições de ensino regular, preconizado pela normativas legais em vigor, são demonstrados pela permanência de ordenamentos patrimonialistas que absorvem a burocracia apenas em sua exterioridade. Desse modo, coexistem os paradigmas da integração e da inclusão no interior das instituições escolares.

Ao se propor para a efetivação da inclusão educacional, a formação continuada dos docentes, em concordância com as normativas investigadas, cria-se a possibilidade de enfraquecer o elemento cultural. A burocracia racional, ao exigir constante conhecimento especializado para o exercício das atribuições do cargo, se apresenta como um recurso para atingir os objetivos de inclusão, pois, por meio dessa contínua qualificação, os docentes poderiam desestabilizar aspectos do seu fazer pedagógico cristalizados em práticas culturais patrimonialistas. Dessa forma, eles teriam a oportunidade de elaborar estratégias de ação diante das especificidades de atendimento ao discente com necessidade educacional específica, garantindo a eficácia da inclusão escolar em seu processo de implantação.

\section{Referências}

Brasil. Lei $n^{o}$. 9.394, de 20 de dezembro de 1996 (1996). Estabelece as diretrizes e bases da educação nacional. Diário Oficial, Brasília.

Brasil. Resolução CNE/CEB $n^{o}$ 2/2001 (2001). Institui as Diretrizes Nacionais para a Educação Especial na Educação Básica. Diário Oficial, Brasília.

Brasil. Política Nacional de Educação Especial na Perspectiva da Educação Inclusiva (2008). Diário Oficial, Brasília.

Brasil. Lei $n^{o}$ 13.146, de 6 de julho de 2015 (2015). Institui a Lei Brasileira de Inclusão de Pessoa com Deficiência (Estatuto da Pessoa com Deficiência). Diário Oficial, Brasília. 
Damatta, R. (1997). Carnavais, malandros e heróis: para uma sociologia do dilema brasileiro (6a ed.). Rio de Janeiro: Rocco.

Faoro, R. (1989). Os donos do poder: formação do patronato político brasileiro (Vol. 2, 8a ed.). São Paulo: Globo.

Gandini, R. P. C. (2005). Patrimonialismo e educação: autoridade doméstica e práticas docentes. Pro-Posições, Campinas, 16 (1), 195-221.

Glat, R., \& Blanco, L. de M. V. (2007) Educação Especial no contexto de um Educação Inclusiva. In R. Glat (Org.). Educação inclusiva: cultura e cotidiano escolar (pp. 15-35). Rio de Janeiro: 7Letras.

Holanda, S. B. de. (1978). Raízes do Brasil (12a ed.). Rio de Janeiro: Livraria José Olympio Editora/INL-MEC.

Lüdke, M., \& André, M. E. D. A (2017). Pesquisa em educação: abordagens qualitativas (2a ed.). Rio de Janeiro: E. P. U.

Mantoan, M.T. E. (1998). Ensino inclusivo/ Educação (de qualidade) para todos. Revista Integração, 8(20), 29-32.

Marconi, M. de A., \& Lakatos, E. M. (1990) Técnicas de pesquisa. São Paulo: Cillas.

Marques. C. A. (1999). Revisão do conceito de normalização em educação especial. Temas sobre Desenvolvimento, 8(44), 16-21.

Mendes, E.G. (1994). Integração escolar: reflexões sobre a experiência de Santa Catarina. Revista Integração, 5(12), 5-19.

Mendonça, E. F. (2000). A regra e o jogo: democracia e patrimonialismo na educação brasileira. Campinas: FE/UNICAMP.

Motta, F. P., \& Pereira, L. C. B. (1980). Introdução à organização burocrática. São Paulo: Brasiliense.

Prieto, R. G. (2006). Atendimento escolar de alunos com necessidades educacionais especiais: um olhar sobre as políticas públicas de educação no Brasil. In V. A. Arantes (Org.). Inclusão escolar: pontos e contrapontos (pp. 31-73). São Paulo: Summus.

Santos, M. P. (1995). Perspectiva histórica do movimento integracionista na Europa. Revista Brasileira de Educação Especial, 2(3).

Sassaki, R. K. (2006). Inclusão: construindo uma sociedade para todos. Rio de Janeiro: WVA.

Severino, A. J. (2007). Metodologia do trabalho científico (23a ed.). São Paulo: Cortez. 
Weber, M. (1972). Economia e sociedade: fundamentos da sociologia compreensiva (Vol. 1, 5a ed.). (R. Barbosa \& K. E. Barbosa, Trad.). Brasília: Universidade de Brasília.

Weber, M. (1974). Burocracia. In M. Weber. Ensaios de sociologia (3a ed.). (W. Dutra, Trad.). Rio de Janeiro: Zahar. p. 229-82.

Weber, M. (1978). Os fundamentos da organização burocrática: uma construção do tipo ideal. In E. Campos (Org.). Sociologia da burocracia (pp. 15-28). São Paulo: Zahar.

Weber, M. (1986). Os três tipos puros de dominação legítima. In G. Cohn (Org.) Weber (pp. 128-141). São Paulo: Ática.

\section{Porcentagem de contribuição de cada autor no manuscrito}

Olgda Laria Borges de Paula $-70 \%$

Edione Teixeira de Carvalho - $30 \%$ 